\title{
Sexual Dysfunction Related to Drugs: a Critical Review. Part V: $\alpha$-Blocker and 5-ARI Drugs
}

Authors

Affiliations

\author{
A. La Torre' ${ }^{1}$, G. Giupponi ${ }^{2}$, D. Duffy ${ }^{2}$, A. Conca ${ }^{2}$, T. Cai ${ }^{3}$, A. Scardigli ${ }^{4}$
}

${ }^{1}$ U.O. di Psichiatria, Ospedale di Rovereto, Rovereto, Italy

${ }^{2}$ Servizio Psichiatrico del Comprensorio Sanitario di Bolzano, Italy

${ }^{3}$ U.O. di Urologia, Ospedale S. Chiara, Trento, Italy

${ }^{4}$ U.O. di Urologia, Ospedale di Rovereto, Italy

\author{
Key words \\ $\alpha$-blockers \\ - 5-ARIs \\ benign prostatic hyperplasia \\ (BPH) drugs \\ - LUTS (lower urinary tract \\ symptoms) drugs \\ - sexual dysfunction \\ - sexual side effects \\ treatment-emergent sexual \\ dysfunction
}

\section{Abstract \\ $\nabla$}

Sexual dysfunction is a potential side effect of BPH (benign prostatic hyperplasia) and LUTS (lower urinary tract symptoms) drugs: this article is a critical review of the current literature. Many studies have been published on this topic. Methodological flaws limit the conclusions of these studies, mainly because of the lack of diagnostic criteria for ejaculatory and sexual desire dysfunction. Few of these studies are RCTs.

The $\alpha$-blocker (also called $\alpha 1$-adrenergic antagonist, alpha-adrenoceptor antagonist, alpha-blocker or $\mathrm{AB}$ ) and 5-ARI (also called $5 \alpha$-reductase inhibitor or testosterone-5-alpha reductase inhibitor) drugs can in particular cause erectile dysfunction, ejaculatory disorders and reduction of sexual desire. The sexual side effect profile of these drugs is different. Among the $\alpha$-blockers, silodosin appears have the highest incidence of ejaculatory disorders. Persistent sexual side effects after discontinuation of finasteride has recently been reported, however further studies are needed to clarify the true incidence and the significance of this finding.

It is desirable that future studies include validated tools to assess and diagnose sexual dysfunction induced by these medications, especially for ejaculation and sexual desire disorders. Only a small amount of research has intentionally set out to investigate sexual dysfunction caused by $\alpha$-blocker and 5-ARI drugs: studies to specifically assess sexual dysfunction induced by these drugs are needed. Further studies are also needed to assess in the long term the role

\section{Introduction}

$\nabla$

In addition to antidepressant, antipsychotic, antiepileptic, benzodiazepine and antihypertensive drugs (for which, see the reviews already of combined therapy of phosphodiesterase type 5 inhibitors and $\alpha$-blockers or 5-ARIs in treating LUTS/BPH.

Methods: This study was conducted in 2014 using the paper and electronic resources of the library of the "Azienda Provinciale per i Servizi Sanitari (APSS)" in Trento, Italy (http://atoz. ebsco.com/Titles/2793). The library has access to a wide range of databases including DYNAMED, MEDLINE Full Text, CINAHL Plus Full Text, The Cochrane Library, Micromedex healthcare series, BMJ Clinical Evidence. The full list of available journals can be viewed at http://atoz.ebsco.com/ Titles/2793, or at the APSS web site (http://www. apss.tn.it).

In completing this review, a literature search was conducted using the key words "benign prostatic hyperplasia drugs", "lower urinary tract symptoms drugs”, “ $\alpha$-blockers”, “5-ARIs”, “sexual dysfunction", "sexual side effects", "treatmentemergent sexual dysfunction", "phosphodiesterase type 5 (PDE5) inhibitors". All resulting listed articles were reviewed. Studies published between 2002 and December 2014 were included in the review.

We included all studies that explicitly reported data on sexual dysfunction during treatment with $\alpha$-blockers and 5-ARIs. We also reviewed studies that have evaluated the use of phosphodiesterase type 5 (PDE5) inhibitors in combination with these drugs.

The purpose was to identify possible intervention strategies for sexual dysfunction related to these drugs. 
It was considered useful to list them according to the ATC system used by the World Health Organization. ATC is an acronym for "Anatomical Therapeutic Chemical" classification system, which can be viewed in detail on the web site of the WHO [5].

In the following table ( $\bullet$ Table 1 ) we have summarized the Anatomical Therapeutic Chemical classification system for $\alpha$-blocker and 5-ARI drugs.

These pharmacologic therapies are employed alone or in combination for the clinical treatment of BPH (Benign Prostatic Hypertrophy), a common disorder among middle-aged and elderly men, which often results in urethral obstruction and LUTS (lower urinary tract symptoms).

Numerous studies have shown that sexual dysfunction is common in older men [6-10].

Also, several clinical and epidemiological studies have clearly demonstrated a consistent and independent association between LUTS/BPH and sexual function in males [9,11-15]. In particular, the severity of LUTS has been shown to correlate with erectile dysfunction and ejaculatory dysfunction in large-scale epidemiological studies [6-8,16-18]. Erectile dysfunction and ejaculatory dysfunction are also side effects of some medical therapies used for the treatment of LUTS caused BPH $[8,19-25]$. A large volume of clinical research has been based on the use of questionnaires for clinical assessment of sexual dysfunction in urological patients. Among these questionnaires, the International Index of Erectile Function (IIEF: a 15-item self-report inventory developed and psychometrically validated to assess the efficacy of pharmacological treatments for erectile dysfunction) is one of the most commonly used [26]. The Sexual Health Inventory for Men (SHIM) is an abridged 5-item version of the IIEF [26]. The Male Sexual Health Questionnaire (MSHQ) contains 25 items in total, which includes a 7-item domain for assessment of ejaculatory dysfunction [27]. An abbreviated version of the MSHQ has recently been published: this short form questionnaire has only a 4-item domain on ejaculation; 3 ejaculatory function items ("force", "volume", and "frequency of ejaculation") and one "ejaculation bother" item [28]. Other self-administered questionnaires or patient-reported outcome measures used in the assessment of sexual function of urological patients also include the Brief Sexual Function Inventory (BSFI: 11 items that focus on sexual function) [29], the International Continence Society Sex Questionnaire (ICS: includes 4 items assessing erectile function, ejaculatory function, pain/discomfort during ejaculation and the extent to which urinary symptoms interfere with sexual function) [30], the Danish Prostate Symptom Score (DAN-PSS: questionnaire used to assess erection, ejaculation, pain/discomfort during ejaculation and the bothersomeness of each of these items) [31] and the Structured Interview on Erectile Dysfunction (SIEDY: a validated, 13-item structured interview that assesses the organic, relational, and psychological components of erectile dysfunction) [32].

\section{Results}

We collected all of the articles listed in the following 2 tables $(\odot$ Table 2,3). In the first table we have indicated the articles on sexual dysfunction related to LUTS and/or BPH drugs, while in the second table we have indicated the articles on PDE5 inhibitors used in LUTS and/or BPH.

As demonstrated in $\odot$ Table 2, the majority of articles are reviews and there are few RCTs (randomized clinical trials, i.e., randomized, double-blind, placebo-controlled studies). The conclusions reached by the various reviews and studies are similar [11-15,18-21,24-26,33-73]. Surprisingly, of the 21 RCTs [74$94]$ reviewed on $\alpha$-blockers and 5-ARIs, only 2 of them $[89,93]$ used a specific and validated rating scale for measuring sexual functioning. In contrast, of the 38 [6-10,16,95-126] non-RCT studies outlined in $\odot$ Table 2 , most of them used a specific questionnaire (IIEF mainly) to detect sexual dysfunction, while 9 studies $[101,103,105,106,115,120,124-126]$ did not use any validated rating scale.

Table 1 "Anatomical Therapeutic Chemical" Classification System: $\alpha$-blocker and 5-ARI drugs.

\begin{tabular}{|c|c|c|c|c|c|}
\hline Anatomical Main Group & Therapeutic Subgroup & Pharmacological Subgroup & Chemical Subgroup & Chemical substance & Main therapeutic use \\
\hline $\begin{array}{l}\text { G } \\
\text { Genito Urinary } \\
\text { System and Sex } \\
\text { Hormones }\end{array}$ & $\begin{array}{l}\text { G04 } \\
\text { Urologicals }\end{array}$ & $\begin{array}{l}\text { G04C } \\
\text { Drugs Used in } \\
\text { Benign } \\
\text { Prostatic } \\
\text { Hypertrophy }\end{array}$ & $\begin{array}{l}\text { G04CA } \\
\text { Alpha- } \\
\text { Adrenoreceptor } \\
\text { Antagonists }\end{array}$ & $\begin{array}{l}\text { Alfuzosin } \\
\text { Tamsulosin } \\
\text { Terazosin } \\
\text { Doxazosin } \\
\text { Silodosin }\end{array}$ & $\begin{array}{l}\text { Drugs Used in } \\
\text { Benign } \\
\text { Prostatic } \\
\text { Hypertrophy }\end{array}$ \\
\hline $\begin{array}{l}\text { G } \\
\text { Genito Urinary } \\
\text { System and Sex } \\
\text { Hormones }\end{array}$ & $\begin{array}{l}\text { G04 } \\
\text { Urologicals }\end{array}$ & $\begin{array}{l}\text { G04C } \\
\text { Drugs Used in } \\
\text { Benign } \\
\text { Prostatic } \\
\text { Hypertrophy }\end{array}$ & $\begin{array}{l}\text { G04CB } \\
\text { Testosterone-5- } \\
\text { Alpha reductase } \\
\text { inhibitors }\end{array}$ & $\begin{array}{l}\text { Dutasteride } \\
\text { Finasteride }\left({ }^{\circ}\right)\end{array}$ & $\begin{array}{l}\text { Drugs Used in } \\
\text { Benign } \\
\text { Prostatic } \\
\text { Hypertrophy }\end{array}$ \\
\hline
\end{tabular}

( ) The 5-ARI inhibitor finasteride is also approved for male pattern hair loss. In the ATC Classification System, this drug is even classified in another group called "other dermatologicals"

Table 2 Total articles on Sexual dysfunction related to LUTS and/or BPH drugs: 154.

$\begin{array}{lll}\begin{array}{l}\text { Reviews } \\ \text { and meta-analysis: }\end{array} & \text { RCTs } & \text { Observational studies (Prospective, } \\ 53 & \text { (Randomized Clinical } & \begin{array}{l}\text { Retrospective or } \\ \text { Case Controls), Open labels, Surveys } \\ \text { Trials): }\end{array} \\ 21 & \text { and Case reports: } \\ & 38\end{array}$

References [11-15,18-21,24-26,33-73] [74-94] [6-10,16,95-126]

The bibliography entries from number 33 onwards have been listed by the year of publication (or by the date of on line access): this order will also be maintained in the text
Other articles:

42

$[1-5,17,22,23,27-32,127-154]$ 
The $\alpha$-blocker and 5-ARI drugs in particular can cause erectile dysfunction, ejaculatory disorders and reduction of sexual desire [59].

We have summarized the main conclusions in the following tables ( $\odot$ Table 4-7).

The sexual side effect profile of these drugs differs. Among the $\alpha$-blockers, silodosin (followed by tamsulosin) appears to have the highest incidence of ejaculatory disorders, up to $28.1 \%$ [92] (for details, see $\odot$ Table 4 ).

The different sexual side effect profile of $\alpha$-blockers could be related to their chemical structure, binding affinity/selectivity for $\alpha 1$-adrenergic receptor subtypes, other receptor-mediated mechanisms, and differential tissue distribution. Alfuzosin, doxazosin, and terazosin demonstrate equal binding to the 3 $\alpha 1$-adrenergic receptor subtypes, while tamsulosin and silodosin exhibit superselective binding to the $\alpha 1 \mathrm{~A}$-receptor $[9,20,54]$.

Table 3 Total articles on PDE-5 inhibitors used in LUTS and/or BPH: 60.

$\begin{array}{llll} & \begin{array}{l}\text { Reviews and } \\ \text { meta-analysis: }\end{array} & \text { RCTs: } & \begin{array}{l}\text { Other Studies } \\ \text { (non RCTs): }\end{array} \\ & \mathbf{2 8} & & \mathbf{9}\end{array}$

The bibliography entries have been listed by the year of publication: this order will also be maintained in the text
The most uroselective $\alpha$-blocker is silodosin, which also has the most marked effect on ejaculation [11].

The sexual side effect profile of dutasteride appears to be similar to that of finasteride with regards to erectile dysfunction (ED), ejaculatory dysfunction (EjD) and decreased libido $[39,112,144]$ : both are associated with a greater risk of ED, EjD, and decreased libido than placebo $[39,66]$. Recently however, Corona et al. [117] found that 5-ARI was associated with a greater risk of decreased libido and spontaneous nocturnal erection, whereas no relationship was found with erectile dysfunction and ejaculation disturbance.

The rate of adverse sexual effects of 5-ARIs becomes comparable to placebo after treatment has been continued for more than 2 years $[33,39,76,103]$. In contrast to these findings, Kaplan et al. [119] recently found that in the long term (5 years), dutasteride resulted in significantly more sexual side effects and breast complications (gynecomastia) than finasteride.

Recently there have been reports of persistent sexual dysfunction after discontinuation of treatment with finasteride $[69,113,118,125,126]$. Irwig and coll. [113] conducted retrospective interviews with 71 otherwise healthy men (age 21-46) who had used finasteride for the treatment of male pattern hair loss, using the validated ASEX (Arizona Sexual Experience Scale) questionnaire. Based on ASEX score results, these researchers found an extremely high incidence of sexual dysfunction in

\begin{tabular}{|c|c|c|c|c|c|}
\hline negative (inhibitory) effect & \multicolumn{5}{|l|}{$(-)$} \\
\hline $\begin{array}{l}\text { no significant effect (com- } \\
\text { parable to placebo) }\end{array}$ & \multicolumn{5}{|l|}{$( \pm)$} \\
\hline $\begin{array}{l}\text { positive (benefical or excita- } \\
\text { tory) effect }\end{array}$ & \multicolumn{5}{|l|}{$(+)$} \\
\hline uncertain results & \multicolumn{5}{|l|}{ (?) } \\
\hline \multicolumn{6}{|c|}{$\begin{array}{l}\text { We have defined the effect of drugs on sexuality as "positive" (+) "negative" (-) or "neutral" ( } \pm \text { ); "uncertain results" (?) refers to findings difficult to inter- } \\
\text { pret. In square brackets we have indicated the reference. }\end{array}$} \\
\hline & Silodosin & Tamsulosin $(\Pi)(\nabla)$ & Alfuzosin (ף) & Terazosin & Doxazosin (ף) \\
\hline Effect on Erectile function & $\begin{array}{l}( \pm) \\
{[89]}\end{array}$ & $\begin{array}{l}( \pm) \\
{[22,23,72,79,97,98,} \\
122,144] \\
(+) \\
{[104,111,121,123]}\end{array}$ & $\begin{array}{l}( \pm) \\
{[22,23,72,77,79,80,144]} \\
(+) \\
{[43,57,83,97,100,102,107} \\
108,110,114,121]\end{array}$ & $\begin{array}{l}( \pm) \\
{[22,23,72,144]} \\
(+) \\
{[111]}\end{array}$ & $\begin{array}{l}( \pm) \\
{[22,23,72,98,144]} \\
(+) \\
{[40,74,95,99,109,111]}\end{array}$ \\
\hline $\begin{array}{l}\text { Effect on Ejaculatory } \\
\text { function }\end{array}$ & $\begin{array}{l}(-) \\
\left(1^{* *}\right) \\
{[20,54,82,} \\
85,87-90,92, \\
94,105,106, \\
115,120]\end{array}$ & $\begin{array}{l}(-) \\
\left(2^{* *}\right) \\
{[20,56,80,81,101} \\
116,123,124]\end{array}$ & $\begin{array}{l}( \pm) \\
{[72,80,83]} \\
(+) \\
{[97,100,102,107,108]}\end{array}$ & $\begin{array}{l}( \pm) \\
{[20,72]}\end{array}$ & $\begin{array}{l}( \pm) \\
{[20,72]} \\
(+) \\
{[99]}\end{array}$ \\
\hline Effect on sexual desire & No data & $\begin{array}{l}(+) \\
{[123]} \\
( \pm) \\
{[55,72,122]}\end{array}$ & $\begin{array}{l}(+) \\
{[97,108]} \\
( \pm) \\
{[55,72]}\end{array}$ & $\begin{array}{l}( \pm) \\
{[55,72]}\end{array}$ & $\begin{array}{l}(+) \\
{[99]} \\
( \pm) \\
{[55,72,75]}\end{array}$ \\
\hline
\end{tabular}

(I) There appears to be conflicting data about the effect on sexual function of alfuzosin, doxazosin and tamsulosin: some research suggests an effect similar to placebo, while other research suggests an improvement. The methodological issues concerning the various studies are detailed in the review by van Dijk et al. [41]. Methodological issues are probably responsible for some of the contradictory findings on sexual adverse events [57]

( $\mathbf{v})$ In the study by Hellstrom et al. almost $90 \%$ of subjects (healthy volunteers) taking $0.8 \mathrm{mg}$ of tamsulosin had at least a $20 \%$ decreased semen volume [81]

$\left(1^{* *}\right)$ The prevalence of ejaculation dysfunction (EjD) induced by silodosin is between 5 to $28.1 \%$, with a median value of about $20 \%$ [148]: silodosin appears to be the drug with the highest risk of EjD [11,20]. Efficacy of silodosin seems to be increased in patients experiencing abnormal ejaculation [115]

$\left(2^{* *}\right)$ The prevalence of ejaculation dysfunction induced by tamsulosin ranges between $3-11 \%[56,72]$ : tamsulosin is associated with a significantly lower risk of ejaculatory disorders than silodosin [20]. In the studies by Hellstrom et al. [81] and Hisasue et al. 2006 [101], ejaculation disorders due to tamsulosin (decreased ejaculate volume and anejaculation) were not attribuited to retrograde ejaculation

Rare instances of priapism have been reported during treatment with $\alpha$-blockers [49]

The study of Leliefeld et al. [96] reaches uncertain results: the $\alpha$-blockers "showed mixed results, but for all aspects there was both improvement and deterioration"

Several authors have considered gynaecomastia as a sexual dysfunction. This side effect has been reported in some research on $\alpha$-blockers [39, 103] 
Table 5 5-ARIs: Type of effect on Sexual function.

\begin{tabular}{|c|c|c|}
\hline negative (inhibitory) effect & \multicolumn{2}{|l|}{$(-)$} \\
\hline no significant effect (comparable to placebo) & \multicolumn{2}{|l|}{$( \pm)$} \\
\hline positive (benefical or excitatory) effect & \multicolumn{2}{|l|}{$(+)$} \\
\hline uncertain results & \multicolumn{2}{|l|}{$(?)$} \\
\hline \multicolumn{3}{|c|}{$\begin{array}{l}\text { We have defined the effect of drugs on sexuality as "positive" (+) "negative" (-) or "neutral” ( } \pm \text { ); "uncertain results" (?) refers to findings difficult to inter- } \\
\text { pret. In square brackets we have indicated the reference. }\end{array}$} \\
\hline & Dutasteride $\left({ }^{*}\right),\left({ }^{* *}\right),\left({ }^{* * *}\right)$ & Finasteride $\left({ }^{*}\right),\left({ }^{* *}\right),\left({ }^{* * *}\right),\left({ }^{* * * *}\right)$ \\
\hline Effect on Erectile function & $\begin{array}{l}(-) \\
{[33,47,67,71,78,84,86,91,112,144]} \\
( \pm) \\
{[117]}\end{array}$ & $\begin{array}{l}(-) \\
{[47,67,71,74-76,93,144]} \\
( \pm) \\
{[117]} \\
(?) \\
{[50]}\end{array}$ \\
\hline Effect on Ejaculatory function & $\begin{array}{l}(-) \\
{[20,33,47,67,71,78,84,86,112,144]} \\
( \pm) \\
{[117]}\end{array}$ & $\begin{array}{l}(-) \\
{[20,47,50,67,71,74-76,93,144]} \\
( \pm) \\
{[117]}\end{array}$ \\
\hline Effect on sexual desire & $\begin{array}{l}(-) \\
{[33,67,71,78,84,86,91,112,117,144]}\end{array}$ & $\begin{array}{l}(-) \\
{[67,71,74-76,93,117,144]}\end{array}$ \\
\hline \multicolumn{3}{|c|}{ 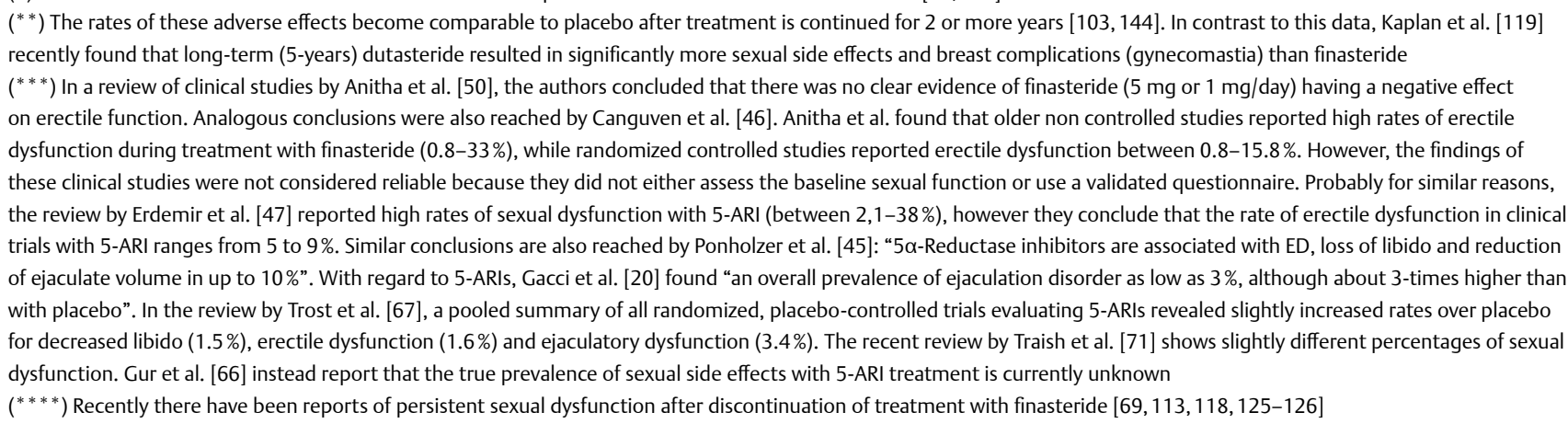 } \\
\hline
\end{tabular}

Table 6 5-ARIs: rates (minimum and maximum percentages) of Sexual Dysfunction in double-blind, randomized, placebo-controlled clinical trials for benign prostatic hyperplasia.

\begin{tabular}{|lll|} 
& finasteride & Dutasteride \\
\hline ED (Erectile Dysfunction) & $3.4-15.8 \%(1.7-6.3 \%)$ & $1.7-11 \%(1.2-3 \%)$ \\
\hline EjD (Ejaculatory Dysfunction) & $0.2-7.7 \%(0.1-1.7 \%)$ & $0.5-2 \%(0.1-1 \%)$ \\
Diminished Sexual Desire & $2.4-13 \%(1.4-2 \%)$ & $0.6-4 \%(0.3-2 \%)$ \\
\hline Placebo effects in studies are shown in parenthesis. Data from Gur et al. [66]
\end{tabular}

patients in this group: between 69 and $94 \%$ of the people interviewed had sexual dysfunction in several categories including "low libido" (94\%), "erectile dysfunction" (92\%), "decreased arousal" (92\%) and "problem with orgasm" (69\%). However, the same authors have acknowledged the limitations of their study, stating that "the true incidence of these events is unknown as this is a post hoc approach" and that in previous randomized, placebo-controlled studies, the incidence of sexual side effects was less than $8 \%$ in the finasteride group and less than $3 \%$ in the control group. "Assuming that the vast majority of these events resolved, the incidence of persistent sexual events in finasteride users would probably be less than $1 \%$ " [113]. In fact, some methodological biases could limit the findings of Irwig et al. Firstly, the study was conducted only through "telephone or spoken Skype standardized interviews". Secondly, the study was carried out on a sample of patients recruited from a website for people complaining of sexual dysfunction. Finally, the study by Irwig et al. was an observational survey (without control groups) and only involved a small number of patients.

The pathophysiology of sexual function produced by 5-ARIs may be related to reduction of dihydrotestosterone levels and probably other neurosteroids such as the metabolites of progesterone $[61,69,147]$. Psychological factors ("nocebo effect") have also been implicated as being responsible for sexual dysfunction in patients treated with 5-ARI drugs [141]. Nevertheless, to date little is known about the exact mechanisms behind 5-ARIrelated sexual dysfunction $[47,63]$.

There is a cumulative risk of sexual side effects with combination therapy (by giving an $\alpha$-blocker with a 5-ARI) when compared to monotherapy or placebo $[37,75,84,86,93]$. Gacci and co-writers [20] found that combination therapy with $\alpha$-blockers and 5-ARIs resulted in a 3-fold increase in the risk of ejaculation disorder as compared with either monotherapies.

Numerous clinical trials seem to confirm that a combination treatment of $\alpha$-blocker and phosphodiesterase type 5 (PDE5) inhibitor is more effective in improving both LUTS and erectile dysfunction, compared to treatment with $\alpha$-blocker alone $[48,165,182,209]$. The results of studies on combination treatment with $\alpha$-blocker and phosphodiesterase type 5 inhibitors in men with ED and BPH have suggested a beneficial synergistic effect of these medications on erectile dysfunction and LUTS $[11,49,152,165]$.

In this review, among the studies of combination treatment with $\alpha$-blockers or 5 -ARIs and phosphodiesterase type 5 inhibitors, 
Table 7 summary of the main conclusions in the literature on sexual dysfunction in patients treated with $\alpha$-blockers and 5-ARIs.

\begin{tabular}{|c|c|}
\hline & $\begin{array}{l}\text { Ejaculatory dysfunction } \\
\text { (EjD): odds ratio (OR) } \\
\text { with a } 95 \% \text { confidence } \\
\text { interval (C.I.). Data from } \\
\text { Gacci et al. [20] }\end{array}$ \\
\hline$\alpha$-blockers vs. placebo & OR: $5.88 ; P<0.0001$ \\
\hline Tamsulosin vs. placebo & OR: $8.58 ; P=0.006$ \\
\hline Silodosin vs. placebo & OR: $32.5 ; P<0.0001$ \\
\hline 5-ARIs vs. placebo & OR: $2.73 ; P<0.0001$ \\
\hline Finasteride vs. placebo & OR: $2.70 ; P<0.0001$ \\
\hline Dutasteride vs. placebo & OR: $2.81 ; P=0.0002$ \\
\hline Combination therapy vs. $\alpha$-blockers alone & OR: $3.75 ; P<0.0001$ \\
\hline Combination therapy vs. 5-ARIs alone & OR: $2.76 ; P=0.02$ \\
\hline \multicolumn{2}{|c|}{$\begin{array}{l}\text { - Tamsulosin was associated with significantly lower risk of EjD than } \\
\text { Silodosin (OR: 0.09; } P<0.00001 \text { ) }\end{array}$} \\
\hline \multicolumn{2}{|c|}{$\begin{array}{l}\text { - Alfuzosin, Doxazosin and Terazosin were associated with a risk of EjD } \\
\text { similar to placebo }\end{array}$} \\
\hline \multicolumn{2}{|c|}{$\begin{array}{l}\text { - Both Finasteride and Dutasteride were associated with significantly } \\
\text { higher risk of EjD than placebo }\end{array}$} \\
\hline \multicolumn{2}{|c|}{$\begin{array}{l}\text { - EjD was significantly more common with combination therapy as com- } \\
\text { pared with } \alpha \text {-blockers alone, or with 5-ARIs alone [20] }\end{array}$} \\
\hline \multicolumn{2}{|c|}{$\begin{array}{l}\text { - } \alpha \text {-blockers (alfuzosin, doxazosin, tamsulosin, terazosin) show an } \\
\text { incidence of decreased libido and of erectile dysfunction (ED) closely } \\
\text { similar to placebo }[39,111]\end{array}$} \\
\hline \multicolumn{2}{|c|}{$\begin{array}{l}\text { - 5-ARIs (finasteride and dutasteride) are associated with a greater risk o } \\
\text { erectile dysfunction (ED), ejaculatory dysfunction (EjD) and decreased } \\
\text { libido than is placebo [39] }\end{array}$} \\
\hline \multicolumn{2}{|c|}{ - the rate of ED in clinical trials on 5-ARIs ranges from 5 to $9 \%$ [47] } \\
\hline
\end{tabular}

we found 16 RCTs on tadalafil $[184,185,187,188,192-195,198-$ 205], 3 RCTs on sildenafil $[183,191,196], 2$ RCTs on vardenafil $[186,197]$ and 2 RCTs on UK-369,003 [189, 190]. The PDE5 inhibitors are used alone or in combination mostly with $\alpha$-blocker alfuzosin or tamsulosin. More recently, PDE5 inhibitors are also used in combination with finasteride [203,204].

These studies reveal the alleviating effect of phosphodiesterase-5 inhibitors on LUTS, as expressed by a reduction of IPSS score (International Prostate Symptom Score), which except for the study by Oelke et al. [195], was not followed by a change in Qmax ("maximum urinary flow rate", which is the urodynamic parameter for assessment of LUTS). The Oelke et al. study [195] is in fact the first to report a significant increase in Qmax, and as such, this finding must be interpreted with caution until confirmed by other studies [149].

The link between erectile dysfunction and LUTS is based on 4 theories: 1) decreased or altered nitrous oxide synthase/nitric oxide levels in the prostate and penile smooth muscle; 2) autonomic hyperactivity effects on LUTS, prostate growth, and erectile dysfunction; 3 ) increased Rho kinase activation/endothelin activity; and 4) pelvic atherosclerosis [14,58,60]. As reported in a recent review, all these major mechanisms of BPH/LUTS could be counteracted by PDE5 inhibitors [160]. Inhibition of PDE5 has been demonstrated to have an effect on several pathogenetic pathways contributing to LUTS, although the exact mechanism of action remains to be clarified [165].

Excluding specific contraindications, all of the studies reviewed and listed in Table 3 [155-214] conclude that the use of PDE5 is both well tolerated and safe in patients with LUTS and/or BPH.

\section{Discussion \\ $\nabla$}

In this review study we found different and seemingly conflicting epidemiological data on sexual dysfunction induced by $\alpha$-blocker and 5-ARI drugs. Several problems make it difficult to quantify and qualify sexual dysfunctions induced by $\alpha$-blocker and 5-ARI drugs. These problems mainly concern the diagnostic criteria of ejaculatory disorders.

None of the studies that we reviewed used the diagnostic criteria for sexual dysfunction proposed by ICD-10 [154], DSM-IV-TR [133] and DSM5 [150] (which receive the greatest international consensus). Other proposed classifications, such as that of $\mathrm{NIH}$ (National Institutes of Health) [128], are rarely used.

To date no clear consensus exists on the classification of "nonpremature ejaculatory dysfunction" [153]. There are no clear diagnostic criteria for delayed ejaculation, as operationalized criteria do not exist [213].

In 2005 Hartman and Waldinger [138] wrote that "a major problem that we should solve is to find consensus on operational definitions of ejaculatory disorders". To the best of our knowledge, the classification of delayed ejaculatory dysfunction is still far from precise. Retarded ejaculation, delayed ejaculation, inadequate ejaculation, inhibited ejaculation, idiopathic anejaculation, (primary) "impotentia ejaculationis", and psychogenic anejaculation have all been used synonymously to describe a delay or absence of male orgasmic response [145]. Furthermore some authors have also included orgasm disorders as ejaculatory disorders [139], while other authors have considered ejaculatory dysfunction as orgasmic dysfunction [72].

The lack of consensus on the diagnostic criteria of ejaculatory disorders makes it difficult to compare the conclusions of the various studies because it is not always clear what the different authors intended.

It is still important to distinguish anejaculation from retrograde ejaculation. Jannini and colleagues [139] have argued that "it is important not to confuse the classification of anejaculation with that of retrograde ejaculation. In the latter, orgasm is usually present, even if blunted, while anejaculation always coincides with anorgasmia (even if the reverse is not true)". Hellstrom et al. [12] and Rosen et al. [143] defined "severe ejaculatory dysfunction as ejaculation with decreased amount of semen or loss of ejaculation". Retrograde ejaculation (or dry ejaculation) occurs when there is entry of semen into the bladder instead of emerging through the penis [153].

Despite this important difference, many studies do not differentiate between anejaculation and retrograde ejaculation.

Examination of "post-ejaculate urine sperm concentration" serves as a reliable indicator of retrograde ejaculation. Nevertheless, only a few studies have researched this data $[81,85,101]$. Other methodological issues include the definition of reduced ejaculatory volume. Previous studies that assessed a reduction in the semen volume could be limited by some methodological bias. Several physiological factors can cause decreased semen volume. For instance, low semen volume can be the result of a short period of sexual abstinence ( $<2$ days) or frequent ejaculations in the period preceding the seminal collection [146]. Therefore the results of any questionnaire or survey can be compromised if you do not define the basic conditions, such as the time period of abstinence prior to analysis of the semen volume. In many studies the period of abstinence prior to the semen analysis was not specified. 
Another possible methodological bias may be due to the fact that in most studies there was no objective measurement of the semen volume and they relied instead on a subjective assessment of semen volume provided by the volunteers (or patients), which carries the risk of incorrect subjective assessment of reduced semen volume. According to Hellstrom et al. [81], "the subjective evaluation of EjD in clinical studies may lead to underestimates of the disorder".

A further methodological bias depends on the lack of definition of semen volume reduction. For example, WHO [146] indicates that the lower reference limit for semen volume is $1.5 \mathrm{ml}$, but none of the studies we reviewed indicated a benchmark for the definition of the reduced volume of ejaculate, except Hellstrom et al. [81], who have defined "ejaculate volume decrease" as "a greater than $20 \%$ decrease from baseline".

The Danish Prostatic Symptom Score (DAN-PSS), a questionnaire published by Hald et al. in 1991 [31] was often used for the detection of ejaculatory disorders. The DAN-PSS is another questionnaire which includes 12 questions related to voiding problems and the perceived bother of each individual symptom and 3 questions concerning sexuality (erection, ejaculation volume, pain/discomfort during ejaculation). This questionnaire has been validated and used in many epidemiologic surveys and clinical trials $[127,129-131,137,140]$. However, to the best of our knowledge it has only been validated for assessing urinary symptoms and not sexual function [30]. This may be a potential limit of studies that have used the DAN-PSS, in that it may have led to an overestimation (or underestimation) of ejaculatory disorders. Rosen et al. [8] found that not only the DAN-PSS, but also the ICS questionnaire have not been psychometrically validated for sexual dysfunction. Both of these questionnaires evaluate only 2 ejaculatory dysfunctions (a reduced amount of semen and pain/discomfort on ejaculation). Rosen et al. [27] have proposed the use of the MSHQ questionnaire ("the only psychometrically and linguistically validated self-administered measure evaluating all components of ejaculation"), but unfortunately there are few studies that have used this questionnaire. As it has been previously highlighted, among the RCTs reviewed on $\alpha$-blockers and 5-ARIs, only $2[89,93]$ of these used a specific and validated rating scale for measuring sexual functioning. In those studies that did not use a patient self-administered questionnaire or patient-reported outcomes, the identification of sexual dysfunction often relies on the spontaneous disclosure by patients, but previous studies have shown that spontaneous reports from patients are infrequent, even though sexual side effects can considerably influence drug compliance [135]. Therefore, failure to use rating scales compromises the accurate assessment of the true rate of sexual dysfunction.

Most researchers have used the term "libido", which unfortunately does not determine which specific phase (desire, arousal or orgasm) of the human sexual response is affected by the sexual dysfunction. In fact, the term "libido" is very generic and does not discriminate between the various phases of the sexual response cycle [136].

In the literature we have found the apparent use of similar expressions of sexual function, which however have probably been interpreted as having different meanings: "loss of sexual desire", "hypoactive sexual desire (HSD)", "hypoactive sexual desire disorder (HSDD)", "low sexual desire", "decreased sex drive (libido)", "loss of libido (sex drive)", "decreased libido". See for example table 2 ("Adverse Events") in the study by Roehrborn et al. [84]. These authors distinguished between "altered (decreased) libido" and "loss of libido", but do not explain the actual difference between these 2 (very similar) terms or why they have differentiated this side effect. Again, in table 1 described in the review by Skolarus et al. [53], "erectile function" is defined in terms of 1) "quality of erection", 2) "libido/ drive" and 3) "satisfaction". However defining erectile function in terms of "libido/drive" can be confusing and difficult to understand for the patient.

\section{Conclusion}

$\nabla$

There have been few rigorous studies utilizing both control groups and validated questionnaires to evaluate the sexual side effects of $\alpha$-blocker and 5-ARI drugs [72].

It is desirable that future studies include validated tools to assess and diagnose sexual dysfunction induced by these medications, especially for ejaculation and sexual desire disorders. Failure to use such assessment questionnaires, reduces the detection of sexual dysfunction and the probability of accurately diagnosing the specific type of sexual dysfunction involved, as well as preventing an objective monitoring of symptom improvement or worsening during the course of drug treatment. MSHQ is a validated questionnaire for the evaluation of sexual dysfunction, in particular for the assessment of the force, delay and pleasure with ejaculation $[8,143]$. Other specific rating scales such as the ASEX [134] or the CSFQ [132] could also be used for patients with LUTS/BPH.

Only a small amount of research has intentionally set out to investigate sexual dysfunction caused by $\alpha$-blocker and 5-ARI drugs. Studies specifically assessing sexual dysfunction induced by these drugs are needed.

Numerous studies show that sexual dysfunction is both highly prevalent and bothersome in sexually active men with LUTS [9]. This implies that sexual dysfunction should be carefully assessed and diagnosed before treating LUTS, as some treatments might further exacerbate it. Additional studies are needed to determine the pathophysiological mechanisms involved in the link between LUTS and sexual dysfunction (especially ejaculation disorders) and the optimal management strategies for men with these concomitant conditions $[8,12]$.

The sexual side effect profile of these urologic drugs is different. Among the $\alpha$-blockers, silodosin (followed by tamsulosin) appears to be the drug with the highest incidence of ejaculatory disorders. Alfuzosin has no deleterious effect on sexual function and is well tolerated when used in combination with low doses of phosphodiesterase type 5 inhibitors for the treatment of ED. Studies suggest that combination treatment with $\alpha$-blocker and phosphodiesterase type 5 inhibitors may act synergistically to improve both LUTS and sexual function [11,49,152,165].

With the only exception of silodosin and, to a lesser extent of tamsulosin, the effect of the $\alpha$-blockers on sexual function appears similar to placebo.

The sexual adverse event profile of dutasteride appears to be similar to that of finasteride.

Recent reports of persistent sexual dysfunction after discontinuation of treatment with finasteride require further studies to assess causality [67].

Further studies are also needed to assess the long-term role of combined therapy of phosphodiesterase type 5 inhibitors and $\alpha$-blockers or 5-ARIs in the treatment LUTS/BPH $[180,197]$. 


\section{Conflict of Interest}

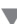

Andres Conca has served as consultant for Lilly, Pfizer and on the speakers' bureau of Lilly, BMS, Astra Zeneca, Lundbeck, Italfarma and Janssen. He reports no conflict of interest with this publication.

\section{References}

1 La Torre A, Giupponi G, Duffy D et al. Sexual dysfunction related to psychotropic drugs: a critical review. Part I: antidepressants. Pharmacopsychiatry 2013; 46: 191-199

2 La Torre A, Conca A, Duffy D et al. Sexual dysfunction related to psychotropic drugs: a critical review. Part II: antipsychotics. Pharmacopsychiatry 2013; 46: 201-208

3 La Torre A, Giupponi G, Duffy DM et al. Sexual dysfunction related to psychotropic drugs: a critical review. Part III: mood stabilizer and anxiolytic drugs. Pharmacopsychiatry 2014; 47: 1-6

4 La Torre A, Giupponi G, Duffy D et al. Sexual dysfunction related to psychotropic drugs: a critical review. Part IV: cardiovascular drugs. Pharmacopsychiatry 2015; 48: 1-6

5 WHO. Collaborating centre for drug statistics methodology. ATC. Structure and principles. Available on line at: http://www.whocc.no/ atc/structure_and_principles/ accessed on 10 December 2014

6 Rosen R, Altwein J, Boyle P et al. Lower urinary tract symptoms and male sexual dysfunction: the multinational survey of the aging male sexual dysfunction: the multinational survey of the aging male (MSAM-7). Eur Urol 2003; 44: 637-649

7 Rosen RC, Altwein J, Boyle P et al. Troubles urinaires du bas appareil et dysfonction sexuelle masculine: l'Enquête MSAM-7 ou Enquête Multinationale de l'Homme Agé. Prog Urol 2004; 14: 332-344

8 Rosen RC, Fitzpatrick JM. Ejaculatory dysfunction in men with lower urinary tract symptoms suggestive of benign prostatic hyperplasia. BJU Int 2009; 104: 974-983

9 Rosen RC, Wei JT, Althof SE et al. Association of sexual dysfunction with lower urinary tract symptoms of BPH and BPH medical therapies: results from the BPH Registry. Urology 2009; 73: 562-566

10 Nickel JC, Elhilali M, Vallancien G. Benign prostatic hyperplasia (BPH) and prostatitis: prevalence of painful ejaculation in men with clinical BPH. BJU Int 2005; 95: 571-574

11 Gacci M, Eardley I, Giuliano F et al. Critical analysis of the relationship between sexual dysfunctions and lower urinary tract symptoms due to benign prostatic hyperplasia. Eur Urol 2011; 60: 809-825

12 Hellstrom WJ, Giuliano F, Rosen RC. Ejaculatory dysfunction and its association with lower urinary tract symptoms of benign prostatic hyperplasia and BPH treatment. Urology 2009; 74: 15-21

13 Kirby M, Chapple C, Jackson G et al. Erectile dysfunction and lower urinary tract symptoms: a consensus on the importance of co-diagnosis. Int J Clin Pract 2013; 67: 606-618

14 McVary K. Lower urinary tract symptoms and sexual dysfunction: epidemiology and pathophysiology. BJU Int 2006; 97: 23-28

15 Taylor JM, DeSouza $R$, Wang $R$. Common approach to managing lower urinary tract symptoms and erectile dysfunction. Asian J Androl 2008; 10: 45-53

16 Li MK, Garcia LA, Rosen R. Lower urinary tract symptoms and male sexual dysfunction in Asia: a survey of ageing men from five Asian countries. BJU Int 2005; 96: 1339-1354

17 Vallancien $G$, Emberton $M$, Harving $N$ et al. Sexual dysfunction in 1,274 European men suffering from lower urinary tract symptoms. J Urol 2003; 169: 2257-2261

18 Yassin A, Saad F, Hoesl CE et al. Alpha-adrenoceptors are a common denominator in the pathophysiology of erectile function and $\mathrm{BPH} /$ LUTS - implications for clinical practice. Andrologia 2006; 38: 1-12

19 Carbone DJ Jr, Hodges S. Medical therapy for benign prostatic hyperplasia: sexual dysfunction and impact on quality of life. Int J Impot Res 2003; 15: 299-306

20 Gacci M, Ficarra V, Sebastianelli A et al. Impact of medical treatments for male lower urinary tract symptoms due to benign prostatic hyperplasia on ejaculatory function: a systematic review and metaanalysis. J Sex Med 2014; 11: 1554-1566

21 Giuliano $F$. Medical treatments for benign prostatic hyperplasia and sexual dysfunction. BJU Int 2008; 102: 8-12

22 AUA Practice Guidelines Committee. AUA guideline on management of benign prostatic hyperplasia. Chapter 1: Diagnosis and treatment recommendations. J Urol 2003; 170: 530-547
23 McVary KT, Roehrborn CG, Avins AL et al. Update on AUA Guideline on the management of benign prostatic hyperplasia. J Urol 2011; 185: 1793-1803

24 Miner M, Rosenberg MT, Perelman MA. Treatment of lower urinary tract symptoms in benign prostatic hyperplasia and its impact on sexual function. Clin Ther 2006; 28: 13-25

25 Rosen R, Giuliano F, Carson CC. Sexual dysfunction and lower urinary tract symptoms (LUTS) associated with benign prostatic hyperplasia (BPH). Eur Urol 2005; 47: 824-837

26 Rosen $R$. Assessment of sexual dysfunction in patients with benign prostatic hyperplasia. BJU Int 2006; 97: 29-33

27 Rosen RC, Catania J, Pollack $L$ et al. Male sexual health questionnaire (MHSQ): scale development and psychometric validation. Urology 2004; 64: 777-782

28 Rosen RC, Catania JA, Stanley E et al. Development and validation of four-item version of Male Sexual Health Questionnaire to assess ejaculatory dysfunction. Urology 2007; 69: 805-808

29 Mykletun A, Dahl AA, O'Leary MP et al. Assessment of male sexual function by the Brief Sexual Function Inventory. BJU Int 2005; 97: 316-323

30 Donovan JL, Abrams P, Peters TJ et al. The ICS-'BPH' Study: the psychometric validity and reliability of the ICSmale questionnaire. $\mathrm{Br}$ J Urol 1996; 77: 554-562

31 Hald T, Nordling J, Andersen JT et al. A patient weighted symptom score system in the evaluation of uncomplicated benign prostatic hyperplasia. Scand J Urol Nephrol Suppl 1991; 138: 59-62

32 Petrone L, Mannucci E, Corona $G$ et al. Structured interview on erectile dysfunction (SIEDY): a new, multidimensional instrument for quantification of pathogenetic issues on erectile dysfunction. Int J Impot Res 2003; 15: 210-220

33 Andriole GL, Kirby R. Safety and tolerability of the dual 5alpha-reductase inhibitor dutasteride in the treatment of benign prostatic hyperplasia. Eur Urol 2003; 44: 82-88

34 Schulman CC. Lower urinary tract symptoms/benign prostatic hyperplasia: minimizing morbidity caused by treatment. Urology 2003; 62: 24-33

35 van Moorselaar J. LUTS and sexual dysfunction: implications for management of BPH. Eur Urol Suppl 2003; 2: 13-20

36 Schiff JD, Mulhall JP. The link between LUTS and ED: clinical and basic science evidence. J Androl 2004; 25: 470-478

37 Lowe FC. Treatment of lower urinary tract symptoms suggestive of benign prostatic hyperplasia: sexual function. BJU Int 2005; 95: $12-18$

38 Marihart S, Harik M, Djavan B. Dutasteride: a review of current data on a novel dual inhibitor of $5 \alpha$ reductase. Rev Urol 2005; 7: 203-210

39 Giuliano F. Impact of medical treatments for benign prostatic hyperplasia on sexual function. BJU Int 2006; 97: 34-38

40 Kaplan SA, De Rose A, Kirby RS et al. Beneficial effects of extendedrelease doxazosin and doxazosin standard on sexual health. BJU Int 2006; 97: 559-566

41 van Dijk MM, de la Rosette JJ, Michel MC. Effects of $\alpha 1$-adrenoceptor antagonists on male sexual function. Drugs 2006; 66: 287-301

42 Wolters JP, Wayne JG, Hellstrom WJG. Current concepts in ejaculatory dysfunction. Rev Urol 2006; 8 (Suppl 4): S18-S25

43 Chung SD, Yu HJ. Impact of treatment of lower urinary tract symptoms suggestive of benign prostatic hyperplasia in ageing men. Incont Pelvic Floor Dysfunct 2007; 1 (Suppl 1): 7-10

44 Naslund M, Martin Miner M. A Review of the clinical efficacy and safety of $5 \alpha$-reductase inhibitors for the enlarged prostate. Clin Ther 2007; 29: 17-25

45 Ponholzer A, Madersbacher S. Lower urinary tract symptoms and erectile dysfunction; links for diagnosis, management and treatment. Int J Impot Res 2007; 19: 544-550

46 Canguven O, Burnett AL. The effect of $5 \alpha$-reductase inhibitors on erectile function. J Androl 2008; 29: 514-523

47 Erdemir F, Harbin A, Hellstrom WJ. 5-alpha reductase inhibitors and erectile dysfunction: the connection. J Sex Med 2008; 5: 2917-2924

48 Giuliano F. Lower urinary tract symptoms and sexual dysfunction: a common approach. BJU Int 2008; 101: 22-26

49 Roehrborn CG, Rosen RC. Medical therapy options for aging men with benign prostatic hyperplasia: focus on alfuzosin $10 \mathrm{mg}$ once daily. Clin Interv Aging 2008; 3: 511-524

50 Anitha B, Inamadar AC, Ragunatha S. Finasteride - its impact on sexual function and prostate cancer. J Cutan Aesthet Surg 2009; 2: $12-16$

51 Kaplan SA. Side effects of $\alpha$-blocker use: retrograde ejaculation. Rev Urol 2009; 11: S14-S18 
52 Liu CC, Huang SP, Lee YC et al. Selecting an appropriate $\alpha 1$-adrenoceptor blocker in the treatment of lower urinary tract symptoms associated with benign prostatic hyperplasia. Incont Pelvic Floor Dysfunct 2009; 3: 73-76

53 Skolarus TA, Wei JT. Measurement of benign prostatic hyperplasia treatment effects on male sexual function. Int J Impot Res 2009; 21: 267-274

54 Rossi M, Roumeguère T. Silodosin in the treatment of benign prostatic hyperplasia. Drug Des Devel Ther 2010; 4: 291-297

55 Wiser HJ, Köhler TS. Sexual impact of the treatment of lower urinary tract symptoms associated with benign prostatic hyperplasia. Curr Urol Rep 2010; 11: 228-235

56 Barkin J. Benign prostatic hyperplasia and lower urinary tract symptoms: evidence and approaches for best case management. Can J Urol 2011; 18: 14-19

57 Hwang TIS. Will medical management of benign prostatic hyperplasia result in better or worse sexual function in men? Urol Sci 2011; 22: $14-18$

58 Lepor $H$. Medical treatment of benign prostatic hyperplasia. Rev Urol 2011; 13: 20-33

59 Mirone V, Sessa A, Giuliano F et al. Current benign prostatic hyperplasia treatment: impact on sexual function and management of related sexual adverse events. Int J Clin Pract 2011; 65: 1005-1013

60 Orabi H, Albersen M, Lue TF. Association of lower urinary tract symptoms and erectile dysfunction: pathophysiological aspects and implications for clinical management. Int J Impot Res 2011; 23: 99-108

61 Traish AM, Hassani J, Guay AT et al. Adverse side effects of $5 \alpha$-reductase inhibitors therapy: persistent diminished libido and erectile dysfunction and depression in a subset of patients. J Sex Med 2011; 8: 872-884

62 Yoshida M, Kudoh J, Homma Y et al. Safety and efficacy of silodosin for the treatment of benign prostatic hyperplasia. Clin Interv Aging $2011 ; 6: 161-172$

63 Mysore V. Finasteride and sexual side effects. Indian Dermatol Online J 2012; 3: 62-65

64 Ding H, Du W, Hou ZZ et al. Silodosin is effective for treatment of LUTS in men with BPH: a systematic review. Asian J Androl 2013; 15: $121-128$

65 Giuliano F, Droupy S. La iatrogénie médicamenteuse en médicine sexuelle. Prog Urol 2013; 23: 804-810

66 Gur S, Kadowitz PJ, Hellstrom WJ. Effects of 5-alpha reductase inhibitors on erectile function, sexual desire and ejaculation. Expert Opin Drug Saf 2013; 12: 81-90

67 Trost L, Saitz TR, Hellstrom WJG. Side effects of 5-alpha reductase inhibitors: a comprehensive review. Sex Med Rev 2013; 1: 24-41

68 Cho HJ, Yoo TK. Silodosin for the treatment of clinical benign prostatic hyperplasia: safety, efficacy, and patient acceptability. Res Rep Urol 2014; 6: 113-119

69 Irwig MS. Persistent sexual and non-sexual adverse effects of finasteride in younger men. Sex Med Rev 2014; 2: 24-35

70 Mitrakas L, Melekos M. Relationship between therapy with A1-adrenoceptor antagonists (A1-blockers) for benign prostatic obstruction and sexual function. J Urol Nephrol 2014; 1: 1-5

71 Traish AM, Mulgaonkar A, Giordano N. The dark side of $5 \alpha$-reductase inhibitors' therapy: sexual dysfunction, high Gleason grade prostate cancer and depression. Korean J Urol 2014; 55: 367-379

72 Welliver C, Butcher M, Potini Y et al. Impact of alpha blockers, 5-alpha reductase inhibitors and combination therapy on sexual function. Curr Urol Rep 2014; 15: 441

$73 \mathrm{Wu} X J$, Zhi Y, Zheng J et al. Dutasteride on benign prostatic hyperplasia: a meta-analysis on randomized clinical trials in 6460 patients. Urology 2014; 83: 539-543

74 Kirby RS, Roehrborn C, Boyle P et al. Efficacy and tolerability of doxazosin and finasteride, alone or in combination, in treatment of symptomatic benign prostatic hyperplasia: the Prospective European Doxazosin and Combination Therapy (PREDICT) trial. Urology 2003; 61: 119-26

75 McConnell JD, Roehrborn CG, Bautista OM et al. The long-term effect of doxazosin, finasteride, and combination therapy on the clinical progression of benign prostatic hyperplasia. N Engl J Med 2003; 349: 2387-2398

76 Wessells H, Roy J, Bannow J et al. Incidence and severity of sexual adverse experiences in finasteride and placebo-treated men with benign prostatic hyperplasia. Urology 2003; 61: 579-584

77 Roehrborn CG, Van Kerrebroeck P, Nordling J. Safety and efficacy of alfuzosin $10 \mathrm{mg}$ once-daily in the treatment of lower urinary tract symptoms and clinical benign prostatic hyperplasia: a pooled analysis of three double-blind, placebo-controlled studies. BJU Int 2003; 92: 257-261
78 Roehrborn CG, Marks LS, Fenter T et al. Efficacy and safety of dutasteride in the four-year treatment of men with benign prostatic hyperplasia. Urology 2004; 63: 709-715

79 Lapitan MCM, Acepcion V, Mangubat J. A Comparative study on the safety and efficacy of tamsulosin and alfuzosin in the management of symptomatic benign prostatic hyperplasia: a randomized controlled clinical trial. J Int Med Res 2005; 33: 562-573

80 Nordling J. Efficacy and safety of two doses (10 and $15 \mathrm{mg}$ ) of alfuzosin or tamsulosin $(0.4 \mathrm{mg})$ once daily for treating symptomatic benign prostatic hyperplasia. BJU Int 2005; 95: 1006-1012

81 Hellstrom WJ, Sikka SC. Effects of acute treatment with tamsulosin versus alfuzosin on ejaculatory function in normal volunteers. J Urol 2006; 176: 1529-1533

82 Kawabe K, Yoshida M, Homma Y. Silodosin a new alpha1 A-adrenoceptor-selective antagonist for treating benign prostatic hyperplasia: results of a phase III randomized, placebo-controlled, double-blind study in Japanese men. BJU Int 2006; 98: 1019-1024

83 Rosen RC, Seftel A, Roehrborn CG. Effects of alfuzosin $10 \mathrm{mg}$ once daily on sexual function in men treated for symptomatic benign prostatic hyperplasia. Int J Impot Res 2007; 19: 480-485

84 Roehrborn CG, Siami P, Barkin J et al. The effects of dutasteride, tamsulosin and combination therapy on lower urinary tract symptoms in men with symptomatic benign prostatic hyperplasia and prostatic enlargement: 2-year results from the CombAT study. J Urol 2008; 179: 616-621

85 Kobayashi K, Masumori N, Kato R et al. Orgasm is preserved regardless of ejaculatory dysfunction with selective a1A-blocker administration. Int J Impot Res 2009; 21: 306-310

86 Roehrborn CG, Siami P, Barkin J et al. The effects of combination therapy with dutasteride and tamsulosin on clinical outcomes in men with symptomatic benign prostatic hyperplasia: 4-year results from the CombAT study. Eur Urol 2010; 57: 123-131

87 Shimizu F, Taguri M, Harada $Y$ et al. Impact of dry ejaculation caused by highly selective alpha1A-blocker: randomized, double-blind, placebo-controlled cross-over pilot study in healthy volunteer men. J Sex Med 2010; 7: 1277-1283

88 Chapple CR, Montorsi F, Tammela TL et al. Silodosin therapy for lower urinary tract symptoms in men with suspected benign prostatic hyperplasia: results of an international, randomized, double-blind placebo- and active-controlled clinical trial performed in Europe. Eur Urol 2011; 59: 342-352

89 Yokoyama $T$, Hara $R$, Fukumoto $K$ et al. Effects of three types of alpha-1 adrenoceptor blocker on lower urinary tract symptoms and sexual function in males with benign prostatic hyperplasia. Int J Urol 2011; 18: 225-223

$90 \mathrm{Yu}$ HJ, Lin AT, Yang SS et al. Non-inferiority of silodosin to tamsulosin in treating patients with lower urinary tract symptoms (LUTS) associated with benign prostatic hyperplasia (BPH). BJU Int 2011; 108: 1843-1848

$91 \mathrm{Na} \mathrm{Y}$, Ye Z, Zhang S. Efficacy and safety of dutasteride in Chinese adults with symptomatic benign prostatic hyperplasia: a randomized, double-blind, parallel-group, placebo-controlled study with an open-label extension. Clin Drug Investig 2012; 32: 29-39

92 Marks LS, Gittelman MC, Hill LA et al. Rapid efficacy of the highly selective $\alpha(1 \mathrm{~A})$-adrenoceptor antagonist silodosin in men with signs and symptoms of benign prostatic hyperplasia: pooled results of 2 phase 3 studies. J Urol 2013; 189 (1 Suppl): S122-S128

$93 \mathrm{Fwu} C W$, Eggers PW, Kirkali Z et al. Change in sexual function in men with lower urinary tract symptoms/benign prostatic hyperplasia associated with long-term treatment with doxazosin, finasteride and combined therapy. J Urol 2014; 191: 1828-1834

94 Choo MS, Song M, Kim JH et al. Safety and efficacy of 8-mg once daily vs 4-mg twice-daily silodosin in patients with lower urinary tract symptoms suggestive of benign prostatic hyperplasia (SILVER Study): a 12-week, double-blind, randomized, parallel, multicenter study. Urology 2014; 83: 875-881

95 De Rose AF, Carmignani $G$, Corbu $C$ et al. Observational multicentric trial performed with doxazosin: evaluation of sexual effects on patients with diagnosed benign prostatic hyperplasia. Urol Int 2002; 68: 95-98

96 Leliefeld HH, Stoevelaar HJ, McDonnel J. Sexual function before and after various treatments for symptomatic benign prostatic hyperplasia. BJU Int 2002; 89: 208-213

97 Elhilali M, Emberton M, Matzkin H et al. Long-term efficacy and safety of alfuzosin $10 \mathrm{mg}$ once daily: a 2-year experience in 'real-life' practice. BJU Int 2006; 97: 513-519 
98 Huang WJ, Chen KK, Chang LS. Correlation between voiding and erectile function in patients with symptomatic benign prostatic hyperplasia. J Chin Med Assoc 2005; 68: 178-118

99 Kirby RS, O'Leary MP, Carson C. Efficacy of extended-release doxazosin and doxazosin standard in patients with concomitant benign prostatic hyperplasia and sexual dysfunction. BJU Int 2005; 95: 103-109

100 van Moorselaar RJ, Hartung R, Emberton $M$ et al. Alfuzosin $10 \mathrm{mg}$ once daily improves sexual function in men with lower urinary tract symptoms and concomitant sexual dysfunction. BJU Int 2005; 95: 603-608

101 Hisasue S, Furuya $R$, Itoh $N$ et al. Ejaculatory disorder caused by alpha- 1 adrenoceptor antagonists is not retrograde ejaculation but a loss of seminal emission. Int J Urol 2006; 13: 1311-1316

102 Nickel JC, Elhilali M, Emberton $M$ et al. The beneficial effect of alfuzosin $10 \mathrm{mg}$ once daily in 'real-life' practice on lower urinary tract symptoms (LUTS), quality of life and sexual dysfunction in men with LUTS and painful ejaculation. BJU Int 2006; 97: 1242-1246

103 Schulman C, Pomerville P, Höfner K et al. Long-term therapy with the dual $5 \alpha$-reductase inhibitor dutasteride is well tolerated in men with symptomatic benign prostatic hyperplasia. BJU Int 2006; 97: 73-80

104 Barqawi AB, Myers JB, O'Donnell C et al. The effect of alpha-blocker and 5alpha-reductase inhibitor intake on sexual health in men with lower urinary tract symptoms. BJU Int 2007; 100: 853-857

105 Kobayashi K, Masumori N, Hisasue S et al. Inhibition of seminal emission is the main cause of anejaculation induced by a new highly selective $\alpha 1$ A-blocker in normal volunteers. J Sex Med 2008; 5: $2185-2190$

106 Nagai A, Hara R, Yokoyama T et al. Ejaculatory dysfunction caused by the new a1-blocker silodosin: A preliminary study to analyze human ejaculation using color Doppler ultrasonography. Int J Urology 2008; 15: 915-918

107 Vallancien G, Emberton M, Alcaraz A et al. Alfuzosin $10 \mathrm{mg}$ once daily for treating benign prostatic hyperplasia: a 3-year experience in reallife practice. BJU Int 2008; 101: 847-852

108 Chung BH, Lee JY, Kim CI et al. Sexuality and the management of BPH with alfuzosin (SAMBA) trial. Int J Impot Res 2009; 21: 68-73

109 Demir O, Ozdemir I, Bozkurt $O$ et al. The effect of $\alpha$-blocker therapy on erectile functions in patients with lower urinary tract symptoms due to benign prostate hyperplasia. Asian J Androl 2009; 11: 716-722

110 Jung JH, Jae SU, Kam SC et al. Correlation between lower urinary tract symptoms (LUTS) and sexual function in benign prostatic hyperplasia: impact of treatment of LUTS on sexual function. J Sex Med 2009; 6: 2299-2304

111 Kumar R, Nehra A, Jacobson DJ et al. $\alpha$-Blocker use is associated with decreased risk of sexual dysfunction. J Urol 2009; 74: 82-87

112 Chi BH, Kim SC. Changes in sexual function in benign prostatic hyperplasia patients taking dutasteride: 1-year follow-up results. Korean J Urol 2011; 52: 632-636

113 Irwig MS, Kolukula S. Persistent sexual side effects of finasteride for male pattern hair loss. J Sex Med 2011; 8: 1747-1753

114 Permpongkosol S, Krilad-O-Larn S, Ratana-O-Larn K. Treatment with a uroselective $\alpha 1$-blocker improves voiding and sexual function: a study in Thai men with lower urinary tract symptoms. J Sex Med 2011; 8: 2582-2589

115 Roehrborn CG, Kaplan SA, Lepor H et al. Symptomatic and urodynamic responses in patients with reduced or no seminal emission during silodosin treatment for LUTS and BPH. Prostate Cancer Prostatic Dis 2011; 14: 143-148

116 Song SH, Son H, Kim KT et al. Effect of tamsulosin on ejaculatory function in BPH/LUTS. Asian J Androl 2011; 13: 846-850

117 Corona G, Rastrelli G, Maseroli $E$ et al. Inhibitors of $5 \alpha$-reductaserelated side effects in patients seeking medical care for sexual dysfunction. J Endocrinol Invest 2012; 35: 915-920

118 Irwig MS. Persistent sexual side effects of finasteride: could they be permanent? J Sex Med 2012; 9: 2927-2932

119 Kaplan SA, Chung DE, Lee RK et al. A 5-year retrospective analysis of $5 \alpha$-reductase inhibitors in men with benign prostatic hyperplasia: finasteride has comparable urinary symptom efficacy and prostate volume reduction, but less sexual side effects and breast complications than dutasteride. Int J Clin Pract 2012; 66: 1052-1055

120 Sakata $K$, Morita $T$. Investigation of ejaculatory disorder by silodosin in the treatment of prostatic hyperplasia. BMC Urology 2012; 12: 29

$121 \mathrm{Jo} H W$, Yoo DS, Ju HT et al. Effect of patient-optimized doses of tamsulosin on erectile function in men with erectile dysfunction and lower urinary tract symptoms. Korean J Urol 2013; 54: 100-105
122 Kim SW, Lee WC, Kim MT et al. Effects of low-dose tamsulosin on sexual function in patients with lower urinary tract symptoms suggestive of benign prostatic hyperplasia. Korean J Urol 2013; 54: 697-702

123 Shelbaia A, Elsaied WM, Elghamrawy H et al. Effect of selective alphablocker tamsulosin on erectile function in patients with lower urinary tract symptoms due to benign prostatic hyperplasia. Urology 2013; 82: 130-135

124 Yoshimura K, Kadoyama K, Sakaeda $T$ et al. A Survey of the FAERS database concerning the adverse event profiles of $\alpha 1$-adrenoreceptor blockers for lower urinary tract symptoms. Int J Med Sci 2013; 10 : 864-869

125 Ganzer CA, Jacobs AR, Iqbal F. Persistent sexual, emotional, and cognitive impairment post-finasteride. A survey of men reporting symptoms. Am J Mens Health 2014; 13 doi:10.1177/1557988314538445

126 Hogan C, Le Noury J, Healy D et al. One hundred and twenty cases of enduring sexual dysfunction following treatment. Int J Risk Saf Med 2014; 26: 109-116

127 Meyoff $H H$, Hald T, Jørgen $N$ et al. A new patient weighted symptom score system (DAN-PSS-1). Clinical assessment of indications and outcomes of transurethral prostatectomy for uncomplicated benign prostatic hyperplasia. Scand J Urol Nephrol 1993; 27: 493-499

128 National Institutes of Health $(\mathrm{NIH})$. NIH Consensus Development Panel on Impotence. JAMA 1993: 270: 83-90

129 Brasso K, Stigsby B, Pilsgård B et al. Precision of a patient-weighted symptom score in prostatism. The DAN-PSS1 questionnaire. Scand J Urol Nephrol 1994; 28: 71-75

130 Hansen BJ, Flyger $H$, Brasso $K$ et al. Validation of the self-administered Danish Prostatic Symptom Score (DAN-PSS-1) system for use in benign prostatic hyperplasia. Br J Urology 1995; 76: 451-458

131 Schou J, Holm NR, Meyhoff HH. Sexual function in patients with symptomatic benign prostatic hyperplasia. Scand J Urol Nephrol Suppl 1996; 179: 119-122

132 Clayton AH, McGarvey EL, Clavet GJ. The Changes in Sexual Functioning Questionnaire (CSFQ): development, reliability and validity. Psychopharmacol Bull 1997; 33: 731-745

133 American Psychiatric Association. Diagnostic and Statistical Manual of Mental Disorders, Fourth Edition, Text Revision (DSM-IV-TR). American Psychiatric Association; Washington D.C: 2000

134 McGahuey CA, Gelenberg AJ, Laukes CA et al. The Arizona Sexual Experience Scale (ASEX): reliability and validity. J Sex Marital Ther 2000; 26: $25-40$

135 Montejo AL, Llorca G, Izquierdo JA et al. Incidence of sexual dysfunction associated with antidepressant agents: a prospective multicenter study of 1022 outpatients. J Clin Psychiatry 2001; 62: 10-21

136 Montgomery SA, Baldwin DS, Riley A. Antidepressant medications: a review of the evidence for drug-induced sexual dysfunction. J Affect Disord 2002; 69: 119-140

137 Engström G, Walker-Engström ML, Henningsohn L et al. Prevalence of distress and symptom severity from the lower urinary tract in men: a population-based study with the DAN-PSS questionnaire. Fam Pract 2004; 21: 617-622

138 Hartmann U, Waldinger MD. Ejaculatory disorders. World J Urol 2005; 23: 67

139 Jannini EA, Lenzi A. Ejaculatory disorders: epidemiology and current approaches to definition, classification and subtyping. World J Urol 2005; 23: 68-75

140 Häkkinen JT, Hakama M, Huhtala H et al. Impact of LUTS Using Bother Index in DAN-PSS-1 Questionnaire. Eur Urol 2007; 51: 473-478

141 Mondaini N, Gontero P, Giubilei G et al. Finasteride $5 \mathrm{mg}$ and sexual side effects: how many of these are related to a nocebo phenomenon? J Sex Med 2007; 4: 1708-1712

142 Sciarra A. Lower urinary tract symptoms (LUTS) and sexual dysfunction (SD): new targets for new combination therapies? Eur Urol 2007; 51: 1485-1487

143 Rosen $R C$, Seftel $A D$. Validated questionnaires for assessing sexual dysfunction and BPH/LUTS: solidifying the common pathophysiologic link. Int J Impot Res 2008; 20: S27-S32

144 Basson R, Incrocci L, Rees $P$ et al. Sexual function in chronic illness and cancer. In: Montorsi F, Basson R, Adaikan G et al (eds.). The $3^{\text {rd }}$ International Consultation on Sexual Medicine - Paris. Health Publication Ltd; 2010

145 McMahon C, Rowland D, Abdo C et al. Disorders of orgasm and ejaculation in men. In: Montorsi F, Basson R, Adaikan G et al (eds.). The $3^{\text {rd }}$ International Consultation on Sexual Medicine - Paris. Health Publication Ltd; 2010 
146 World Health Organization. WHO laboratory manual for the examination and processing of human semen $-5^{\text {th }}$ ed. WHO Press; Geneva, Switzerland: 2010

147 Goldstein I, Evans MA. An old problem with a new cause - 5 alpha reductase inhibitors and persistent sexual dysfunction. J Sex Med 2011; 8: 1829-1831

148 Morgia G. Does the use of silodosin to treat benign prostatic hyperplasia really offer something new? Eur Urol 2011; 59: 353-355

149 Chapple CR. Monotherapy with a-blocker or phosphodiesterase 5 inhibitor for lower urinary tract symptoms? Eur Urol 2012; 61: 926-927

150 American Psychiatric Association. Diagnostic and Statistical Manual of Mental Disorders. Fifth Edition (DSM-5)Arlington, VA: 2013

151 McMahon CG, Jannini E, Waldinger $M$ et al. Standard operating procedures in the disorders of orgasm and ejaculation. J Sex Med 2013; 10: 204-229

152 Oelke M, Bachmann A, Descazeaud A et al. EAU Guidelines on the treatment and follow-up of non-neurogenic male lower urinary tract symptoms including benign prostatic obstruction. Eur Urol 2013; 64: $118-140$

153 Seyam $R$. A systematic review of the correlates and management of nonpremature ejaculatory dysfunction in heterosexual men. Ther Adv Urol 2013; 5: 254-297

154 WHO. International Classification of Diseases (ICD) and Related Health Problems. $10^{\text {th }}$ Revision (ICD-10). Available online at: http:// apps.who.int/classifications/icd10/browse/2010/en\#/V (accessed on 10 December 2014)

155 Carson CC. Combination of phosphodiesterase-5 inhibitors and a-blockers in patients with benign prostatic hyperplasia: treatments of lower urinary tract symptoms, erectile dysfunction, or both? BJU Int 2006; 97: 39-43

156 Gonzalez RR, Kaplan SA. Tadalafil for the treatment of lower urinary tract symptoms in men with benign prostatic hyperplasia. Expert Opin Drug Metabol Toxicol 2006; 2: 609-617

157 Gales BJ, Gales MA. Phosphodiesterase-5 inhibitors for lower urinary tract symptoms in men. Ann Pharmacother 2008; 42-1: 11-15

158 Giannitsas K, Mitropoulos D, Kostantinopoulos A et al. Phosphodiesterase-5 inhibitors in the treatment of lower urinary tract symptoms and benign prostatic hyperplasia. Expert Opin Pharmacother 2008; 8: 1687-1693

159 Caremel R, Oger-Roussel S, Behr-Roussel D et al. Traitement des troubles du bas appareil urinaire liés à une hyperplasie bénigne de prostate par inhibiteur de la phosphodiestérase type 5. Prog Urol 2010; 20: 616-626

160 Andersson KE, de Groat WC, McVary K et al. Tadalafil for the treatment of lower urinary tract symptoms secondary to benign prostatic hyperplasia: Pathophysiology and mechanism(s) of action. Neurourol Urodyn 2011; 30: 292-301

161 Martínez-Salamanca JI, Carballido J, Eardley I et al. Phosphodiesterase type 5 inhibitors in the management of non-neurogenic male lower urinary tract symptoms: critical analysis of current evidence. Eur Urol 2011; 60: 527-535

162 Ückert S, Oelke M. Phosphodiesterase (PDE) inhibitors in the treatment of lower urinary tract dysfunction. Br J Clin Pharmacol 2011; 72: 197-204

163 Curran MP. Tadalafil: in the treatment of signs and symptoms of benign prostatic hyperplasia with or without erectile dysfunction. Drugs Aging 2012; 29: 771-781

164 Elterman DS, Chughtai B, Lee RK et al. Update on phosphodiesterase type 5 inhibitors for the treatment of lower urinary tract symptoms due to benign prostatic hyperplasia. Rev Urol 2012; 14: 79-86

165 Gacci $M$, Corona $G$, Salvi $M$ et al. A systematic review and metaanalysis on the use of phosphodiesterase 5 inhibitors alone or in combination with $\alpha$-blockers for lower urinary tract symptoms due to benign prostatic hyperplasia. Eur Urol 2012; 61: 994-1003

166 Zhao C, Park JK. Phosphodiesterase type 5 inhibitor and erectile dysfunction in lower urinary tract symptoms. LUTS 2012; 4: 75-80

167 Dong $Y$, Hao L, Shi $Z$ et al. Efficacy and safety of tadalafil monotherapy for lower urinary tract symptoms secondary to benign prostatic hyperplasia: a meta-analysis. Urol Int 2013; 91: 10-18

168 Gacci M, Salvi M, Sebastianelli A et al. The use of a single daily dose of tadalafil to treat signs and symptoms of benign prostatic hyperplasia and erectile dysfunction. Res Rep Urol 2013; 5: 99-111

169 Giuliano F, Ückert S, Maggi M et al. The mechanism of action of phosphodiesterase type 5 inhibitors in the treatment of lower urinary tract symptoms related to benign prostatic hyperplasia. Eur Urol 2013; 63: 506-516
170 Giuliano F, Rouprêt $M$, Doridot $G$ et al. Effets des inhibiteurs de la phosphodiestérase de type 5 sur les symptômes du bas appareil urinaire associés à une hypertrophie bénigne de la prostate. Prog Urol 2013; 23: 283-295

171 Lythgoe C, McVary KT. The use of PDE-5 inhibitors in the treatment of lower urinary tract symptoms due to benign prostatic hyperplasia. Curr Urol Rep 2013; 14: 585-594

172 Miller S. Role of phosphodiesterase type 5 inhibitors for lower urinary tract symptoms. Ann Pharmacother 2013; 47: 278-283

173 No authors listed. Tadalafil for benign prostatic hyperplasia. Drug Ther Bull 2013; 51: 93-96

174 Park HJ, Won JEJ, Sorsaburu S et al. Urinary tract symptoms (LUTS) secondary to benign prostatic hyperplasia(BPH) and LUTS/BPH with erectile dysfunction in Asian men: a systematic review focusing on tadalafil. World J Mens Health 2013; 31: 193-207

175 Porst $H$, Roehrborn CG, Secrest RJ et al. Effects of tadalafil on lower urinary tract symptoms secondary to benign prostatic hyperplasia and on erectile dysfunction in sexually active men with both conditions: analyses of pooled data from four randomized, placebo-controlled tadalafil clinical studies. J Sex Med 2013; 10: 2044-2052

176 Alsaikhan B, Alrabeeah K, Carrier S. Management options for the treatment of benign prostatic hyperplasia with or without erectile dysfunction: a focus on tadalafil and patient considerations. Int J Gen Med 2014; 7: 271-276

177 Govorov A, Kasyan G, Priymak D et al. Tadalafil in the management of lower urinary tract symptoms: a review of the literature and current practices in Russia. Cent European 2014; 67: 167-177

178 Hatzimouratidis $K$. A review of the use of tadalafil in the treatment of benign prostatic hyperplasia in men with and without erectile dysfunction. Ther Adv Urol 2014; 6: 135-147

179 Lee SW, Paick JS, Park HJ et al. The efficacy and safety of tadalafil 5 mg once daily in Korean men with lower urinary tract symptoms suggestive of benign prostatic hyperplasia: an integrated analysis. World J Mens Health 2014; 32: 28-35

180 Wang X, Wang X, Li S et al. Comparative effectiveness of oral drug therapies for lower urinary tract symptoms due to benign prostatic hyperplasia: a systematic review and network meta-analysis. PLoS ONE 2014; 9: e107593 doi:10.1371/journal.pone.0107593

181 Wronski S. The new horizons of pharmacotherapy. Unexpected pharmacological actions and a new therapeutic strategy of phosphodiesterase-5 inhibitors. Cent European J Urol 2014; 67: 314-318

182 Yan H, Zong H, Cui Y et al. The efficacy of PDE5 inhibitors alone or in combination with alpha-blockers for the treatment of erectile dysfunction and lower urinary tract symptoms due to benign prostatic hyperplasia: a systematic review and meta-analysis. J Sex Med 2014; 11: 1539-1545

183 McVary KT, Monnig W, Camps JL Jr et al. Sildenafil citrate improves erectile function and urinary symptoms in men with erectile dysfunction and lower urinary tract symptoms associated with benign prostatic hyperplasia: a randomized, double-blind trial. J Urol 2007; 177: 1071-1077

184 McVary KT, Roehrborn CG, Kaminetsky JC et al. Tadalafil relieves lower urinary tract symptoms secondary to benign prostatic hyperplasia. J Urol 2007; 177: 1401-1407

185 Bechara A, Romano S, Casabé A et al. Comparative efficacy assessment of tamsulosin vs. tamsulosin plus tadalafil in the treatment of LUTS/ BPH. Pilot study. J Sex Med 2008; 5: 2170-2178

186 Stief CG, Porst $H$, Neuser $D$ et al. A randomised, placebo-controlled study to assess the efficacy of twice-daily vardenafil in the treatment of lower urinary tract symptoms secondary to benign prostatic hyperplasia. Eur Urol 2008; 53: 1236-1244

187 Roehrborn CG, McVary KT, Elion-Mboussa A et al. Tadalafil administered once daily for lower urinary tract symptoms secondary to benign prostatic hyperplasia: a dose finding study. J Urol 2008; 180 : 1228-1234

188 Broderick GA, Brock GB, Roehrborn CG et al. Effects of tadalafil on lower urinary tract symptoms secondary to benign prostatic hyperplasia in men with or without erectile dysfunction. Urology 2010; 75: $1452-1458$

189 Giuliano F, Lamb J, Crossland A et al. A placebo-controlled exploratory study investigating the efficacy and safety of the phosphodiesterase type 5 inhibitor UK-369,003 for the treatment of men with storage lower urinary tract symptoms associated with a clinical diagnosis of overactive bladder. BJU Int 2010; 106: 666-673 
190 Tamimi NA, Mincik I, Haughie S et al. A placebo-controlled study investigating the efficacy and safety of the phosphodiesterase type 5 inhibitor UK-369,003 for the treatment of men with lower urinary tract symptoms associated with clinical benign prostatic hyperplasia. BJU Int 2010; 106: 674-680

191 Tuncel A, Nalcacioglu V, Ener K et al. Sildenafil citrate and tamsulosin combination is not superior to monotherapy in treating lower urinary tract symptoms and erectile dysfunction. World J Urol 2010; 28: $17-22$

192 Kim SC, Park JK, Kim SW et al. Tadalafil administered once daily for treatment of lower urinary tract symptoms in Korean men with benign prostatic hyperplasia: results from a placebo-controlled pilot study using tamsulosin as an active control. LUTS 2011; 3: 86-93

193 Porst H, Kim ED, Casabé AR et al. Efficacy and safety of tadalafil once daily in the treatment of men with lower urinary tract symptoms suggestive of benign prostatic hyperplasia: results of an international randomized, double-blind, placebo-controlled trial. Eur Urol 2011; 60: $1105-1113$

194 Egerdie RB, Auerbach S, Roehrborn CG et al. Tadalafil 2.5 or $5 \mathrm{mg}$ administered once daily for 12 weeks in men with both erectile dysfunction and signs and symptoms of benign prostatic hyperplasia: results of a randomized, placebo-controlled, double-blind study. J Sex Med 2012; 9: 271-281

195 Oelke M, Giuliano F, Mirone V et al. Monotherapy with tadalafil or tamsulosin similarly improved lower urinary tract symptoms suggestive of benign prostatic hyperplasia in an international, randomised, parallel, placebo-controlled clinical trial. Eur Urol 2012; 61: 917-925

196 Öztürk MI, Kalkan S, Koca O et al. Efficacy of alfuzosin and sildenafil combination in male patients with lower urinary tract symptoms. J Androl 2012; 44: 791-795

197 Gacci M, Vittori G, Tosi $N$ et al. A randomized, placebo-controlled study to assess safety and efficacy of vardenafil $10 \mathrm{mg}$ and tamsulosin $0.4 \mathrm{mg}$ vs. tamsulosin $0.4 \mathrm{mg}$ alone in the treatment of lower urinary tract symptoms secondary to benign prostatic hyperplasia. J Sex Med 2012; 9: 1624-1633

198 Takeda M, Nishizawa O, Imaoka T et al. Tadalafil for the treatment of lower urinary tract symptoms in Japanese men with benign prostatic hyperplasia: results from a 12-week placebo-controlled dose-finding study with a 42-week open-label extension. LUTS 2012; 4: 110-119

199 Brock G, Broderick G, Roehrborn CG et al. Tadalafil once daily in the treatment of lower urinary tract symptoms (LUTS) suggestive of benign prostatic hyperplasia (BPH) in men without erectile dysfunction. BJU Int 2013; 112: 990-997

200 Dmochowski R, Roehrborn C, Klise S et al. Urodynamic effects of once daily tadalafil in men with lower urinary tract symptoms secondary to clinical benign prostatic hyperplasia: a randomized, placebo controlled 12-week clinical trial. J Urol 2013; 189 (1 Suppl): S135-S140

201 Giuliano F, Oelke M, Jungwirth A et al. Tadalafil once daily improves ejaculatory function, erectile function, and sexual satisfaction in men with lower urinary tract symptoms suggestive of benign prostatic hyperplasia and erectile dysfunction: results from a randomized, placebo- and tamsulosin-controlled, 12-week double-blind study. J Sex Med 2013; 10: 857-865
202 Yokoyama O, Yoshida M, Kim SC et al. Tadalafil once daily for lower urinary tract symptoms suggestive of benign prostatic hyperplasia: a randomized placebo- and tamsulosin-controlled 12-week study in Asian men. Int J Urol 2013; 20: 193-201

203 Casabé A, Roehrborn CG, Da Pozzo LF et al. Efficacy and safety of the coadministration of tadalafil once daily with finasteride for 6 months in men with lower urinary tract symptoms and prostatic enlargement secondary to benign prostatic hyperplasia. J Urol 2014; 191 : 727-733

204 Glina S, Roehrborn CG, Esen A et al. Sexual function in men with lower urinary tract symptoms and prostatic enlargement secondary to benign prostatic hyperplasia: results of a 6 -month, randomized double-blind, placebo-controlled study of tadalafil coadministered with finasteride. J Sex Med 2015; 12: 129-138; early view (online version of record published before inclusion in an issue), article first published online 29 OCT 2014, doi:10.1111/jsm.12714

205 Takeda M, Yokoyama O, Lee SW et al. Tadalafil $5 \mathrm{mg}$ once-daily therapy for men with lower urinary tract symptoms suggestive of benign prostatic hyperplasia: results from a randomized, double-blind, placebo-controlled trial carried out in Japan and Korea. Int J Urol 2014; 21: 670-675

206 De Rose AF, Giglio M, Traverso P et al. Combined oral therapy with sildenafil and doxazosin for the treatment of non-organic erectile dysfunction refractory to sildenafil monotherapy. Int J Impot Res 2002; 14: 50-53

207 Sairam K, Kulinskaya E, McNicholas TA et al. Sildenafil influences lower urinary tract symptoms. BJU Int 2002; 90: 836-839

208 Mulhall JP, Guhring P, Parker M et al. Assessment of the impact of sildenafil citrate on lower urinary tract symptoms in men with erectile dysfunction. J Sex Med 2006; 3: 662-667

209 Kaplan SA, Gonzalez RR, Te AE. Combination of alfuzosin and sildenafil is superior to monotherapy in treating lower urinary tract symptoms and erectile dysfunction. Eur Urol 2007; 51: 1717-1723

210 Liguori G, Trombetta C, De Giorgi G et al. Efficacy and safety of combined oral therapy with tadalafil and alfuzosin: an integrated approach to the management of patients with lower urinary tract symptoms and erectile dysfunction. Preliminary report. J Sex Med 2009; 6: 544-552

211 MacDiarmid SA, Hill LA, Volinn $W$ et al. Lack of pharmacodynamic interaction of silodosin, a highly selective $\alpha 1$ a-adrenoceptor antagonist, with the phosphodiesterase-5 inhibitors sildenafil and tadalafil in healthy men. Urology 2010; 75: 520-525

212 Donatucci CF, Brock GB, Goldfischer ER et al. Tadalafil administered once daily for lower urinary tract symptoms secondary to benign prostatic hyperplasia: a 1-year, open-label extension study. BJU Int 2011; 107: 1110-1116

213 Lee JY, Park SY, Jeong TY et al. Combined tadalafil and $\alpha$-blocker therapy for benign prostatic hyperplasia in patients with erectile dysfunction: a multicenter, prospective study. J Androl 2012; 33: 397-403

214 Singh DV, Mete UK, Mandal AK et al. A comparative randomized prospective study to evaluate efficacy and safety of combination of tamsulosin and tadalafil vs. tamsulosin or tadalafil alone in patients with lower urinary tract symptoms due to benign prostatic hyperplasia. J Sex Med 2014; 11: 187-196 